\title{
Entrepreneurs' motivation: Goal striving among entrepreneurs in the new venture creation process
}

\begin{abstract}
Goal striving, the enactment of motivation, is central to new venture creation. This paper presents two independent studies, one utilizing panel data from a 36-month period and the other utilizing a fine grained journal entries of eight cases over a six-month period that provide a broad and detailed examination of entrepreneurs' goal striving. The results show that successful entrepreneurs set multiple clear, specific, and actionable goals that are focused on the venture and offer clear feedback on whether a goal is attained, and can be pursued simultaneously. These results provide insight into entrepreneurs' goal striving towards venture creation.
\end{abstract}

Keywords: entrepreneurs, motivation, goal striving

\section{INTRODUCTION}

In new venture creation, it is suggested that entrepreneurs' motivation acts as an antecedent and facilitator of behavior throughout the process (Dunkelberg, Moore, Scott, \& Stull, 2013). The general impact motivation has on entrepreneurs' choice, intention, and behavior is acknowledged in the entrepreneurship literature (Bird, 1989; Naffziger, Hornsby \& Kuratko, 1994). However, the specific impact motivation has on behaviors in the new venture creation process is not well understood and has received scant attention from entrepreneurship scholars (Shane, Baum, \& Collins, 2003).

Motivation is inferred from the direction, intensity, and persistence of efforts (e.g., Locke \& Latham, 2004). The centrality of motivation in the organizational behavior and psychology literatures reflects its explanatory power of human behavior. The motivation literature shows that goals are "internal representations of desired states" (Austin \& Vancouver, 1996, 338) or "something an individual wants to attain" (Locke \& Latham, 1990, 7). As such, goals are at the center of most, if not all, motivation theories (Mitchell, 1997). Scholars point out that motivation consists of two main parts: goal setting and goal striving (James, 1890; Gollwitzer, 1990). Goal setting has dominated the motivation literature thus far (Locke \& Latham, 1990, 2004) as 
researchers have focused on empirical testing of goal setting or parts thereof (Steers, Mowday, \& Shapiro, 2004).

Goals and intentions are related but distinct constructs. A "goal" refers to a desired end state, while an "intention" refers to a mental state representing a promise to carry out an action in the future. These two constructs are related with respect to a focus on the future and in that they imply a common direction and likelihood of subsequent action. The notion of intentions has been dominating in the recent the entrepreneurship literature - one that has produced fruitful theoretical advancements (e.g., Krueger \& Brazeal, 1994). Yet, meta-analyses illustrate that intention models explain about 21 to 37 percent of variance in intentions and behavior (Armitage \& Conner, 2001; Schlaegel \& Koenig, 2014). While a set goal per se is similar to an intention, goal striving is a process that is based on behavioral outcomes. Therefore, goal striving holds potential to gain insight to entrepreneurs' behavior in the new venture creation process as it focuses explicitly on the variation in pattern of observable behaviors entrepreneurs engage in as part of the new venture creation process.

The purpose of this research is to examine entrepreneurs' goal striving in new venture creation to extend the conversation on how some but not other entrepreneurs successfully launch new ventures. In this research, entrepreneurs refer to people in the process of creating new ventures (Gartner, 1988), which by some a referred to as nascent entrepreneurs (cf. Gartner, Shaver, Carter, \& Reynolds, 2004). This study advances the literature on entrepreneurs' behavior by evidencing successful entrepreneurs' goal striving is characterized by breaking the overall goal of new venture creation into a large number of clear, small, context specific, and actionable goals that pertain to the new venture creation, offer feedback on goal accomplishment, and are pursued simultaneously. 


\section{ENTREPRENUERS' GOAL STRIVING PROCESS}

Entrepreneurs are considered creator of new ventures by entrepreneurship scholars (Gartner, 1988, Shane \&Venkataraman, 2000) meaning that the overarching goal of entrepreneurs is new venture creation. This is a self-set goal that creates a discrepancy between the situation the person is currently in and the desirable situation of being an entrepreneur with a new venture. Through goal striving an entrepreneur seeks to minimalize or eliminate this discrepancy between the present situation and the desirable situation of being an entrepreneur with a new venture. The goal striving process is based on three interrelated constructs: (1) goal dimensions (Austin \& Vancouver, 1996; Locke \& Latham, 1990; Vroom, 1964); (2) goal striving progress (Carver Scheier, 1990, 1998; Powers, 1973, 2005); and (3) goal attainment (Locke \& Latham, 1990).

\section{Goal Dimensions}

Goal dimensions refer to an entrepreneur's perception of a goal (Austin \& Vancouver, 1996). Goal setting theory and expectancy theory (Locke \& Latham, 1990; Vroom, 1964) illustrate that a key aspect in goal setting is goal content: "the object or result being sought" (Locke \& Latham, 1990, 25). Goal content also includes goal specificity; or the clarity of a goal.

\section{Goal Striving Progress}

In situations such as new venture creation the goal striving progress is undoubtedly a complex phenomenon (Austin \& Vancouver, 1996). This is in part because the successful achievement of such a goal involves time lags (Krueger, 2007), dependencies on interim thoughts and behaviors directed toward the attainment of multiple intermediate goals (Carver \& Scheier, 1990, 1998). Progress assessment is particularly important in situations in which multiple goals are pursued simultaneously and entrepreneurs have to make decisions regarding 
allocation of efforts (Naylor \& Ilgen, 1984). In addition, an entrepreneur is continuously required to make decisions on how and where to direct efforts toward the goal striving progress by setting new or revising smaller goals depending of feedback on goal attainment (Austin \& Vancouver, 1996; Carver \& Scheier, 1990, 1998).

Goal striving is a continuous process that is based on feedback control (Carver \& Scheier, 1990, 1998; Vancouver, 2005; Vallacher \& Wegner, 1987, 2012). It is essentially an internal guidance system that results in behavior (Higgins, 1987, 1997). The goal striving process is based on a hierarchy of goals and feedback from each level in the goal hierarchy (Powers, 1973, 2005). At each level, the process is based on a comparison of a person's perception of the situation and a reference point — that is, a desirable state or outcome, the overarching goal. The person's perception of the situation is based on a combination of environmental factors, outside influences, personal experiences, etc. When compared, these two may result in behavior. If these two are aligned, no action is taken. In contrast, if the two are not aligned, action is taken by the entrepreneur to reduce the discrepancy. The output of this process then alters to the person's perception of the situation, and the process is repeated based on the revised perception of the situation until the discrepancy is minimized to an acceptable level or eliminated (Carver \& Scheier, 1990, 1998). This process guides entrepreneurs' behavior and progress towards overarching goal attainment (Locke, Shaw, Saari, \& Latham, 1981).

To launch a new venture, entrepreneurs need to pursue multiple goals simultaneously (Reynolds, 2010). Consistent with the fundamental assumption of feedback control (Carver \& Scheier, 1990, 1998; Vancouver, 2005; Vallacher \& Wegner, 1987, 2012), Powers (1973, 2005) argues that there are multiple (as opposed to a single) feedback loops operating simultaneously. Further, he argues that these feedback loops are ordered into a hierarchy, prioritized in terms of 
immediate importance when he points out that the output of a superordinate feedback loop provides, or resets, the reference point of the next lower level feedback loop, the goal of the next lower level. Such observation implies the reference point depends, at least in part, on previous perceptions and actions that have been proven to reduce the perceived discrepancy between the person's perception of the situation and the reference point (a goal). Powers $(1973,2005)$ also observes that a reference point (a goal) that is specified as behavioral outcomes becomes more concrete (clear and specific) and actionable (and, in turn, provides clear feedback on whether the goals is attained) as a person moves to lower levels in the hierarchy of goals. Lastly, he suggests that the nature of a higher level goal, the behavioral outcome (the feedback on goal attainment) from the higher level provides reference points (goals) for the next lower level, and resetting of the reference points (the goals), the goal at the next lower level is maintained throughout the hierarchy, making it a hierarchy of goals. Similar arguments are inherent in Action Identification Theory (Vallacher \& Wegner, 1987, 2012).

Placing this goal hierarchy process in the context of entrepreneurs' goal striving may be described in a sequential fashion. A person first establishes a goal of being happy. In the pursuit of happiness, the person then considers family, leisure activities, time, employment, and more. At the next lower level pertaining to employment, the person may choose organizational employment or self-employment. If the choice is self-employment, the options may include buying a business or creating a new venture. As this sequential pattern illustrates, the goals become more specific and actionable and hold potential for obtaining clear feedback on goal attainment as the entrepreneur moves to lower levels in the hierarchy of goals.

\section{Goal Attainment}


Goal attainment is typically referred to as the outcome of goal-directed behavior (Klein \& Kim, 1998; Sagie, 1996). In effect, goal attainment answers the question "to what degree has the goal been accomplished?" In entrepreneurship, goal attainment can be assessed by considering whether the goals set forth in a business plan have been accomplished or not, such as whether or not the first sales has been made or the new venture is launched. In situations in which goal striving is continuous, goal attainment may be considered in terms of an estimate of goal attainment (Austin \& Vancouver, 1996). In the context of the goal hierarchy, goal attainment provides a reference point in the feedback loop as it will show whether the discrepancy is reduced to an acceptable degree and a new goal is to be set or additional efforts should be taken to further reduce the discrepancy or the goal should be revised.

\section{Hypotheses}

Placing goal dimensions, goal striving, and goal attainment in the context of the new venture creation process model proposed by Stevenson, Roberts, and Grousbeck (1985) produces two hypotheses. Part of goal dimensions is goal content, or the nature of the goals. Considering goal contents in relation to the four phases of the new venture creation process model (Stevenson et al., 1985) indicates that as the nature of the goals changes as the new venture creation progresses. This means that the nature of the initial goals will change as the goals are attained resulting in new goals are focusing on another aspect of the new venture creation. Thus, it is hypothesized:

H1: The natures of the set goals change as previous goals are attained.

The overall goal of new venture creation is to create a new venture-a seemingly overwhelming goal at the outset of the start-up process for many. As a result, and in accordance with the process inherent in hierarchy of goals, this overall goal is broken into a large number of 
small goals at a lower hierarchical level. This process of breaking down of the overall goal into smaller goals at lower levels results in a revised set of goals that are clear and specific, becoming actionable and offering clear feedback on whether they are attained. It also results in a new or revised set of reference points. Lastly, due to the smaller size and number, these smaller goals are pursued simultaneously in the new venture creation process. Therefore, it is hypothesized:

H2: A large number of clear, small, specific, and actionable goals that provide clear feedback on goal attainment focused on the creation of a venture, not the entrepreneurs per se, is associated with new venture creation success.

\section{METHOD AND RESULTS OF TWO STUDIES}

Two independent studies form the basis for this longitudinal research. The first study is based on the PSED I data from across multiple waves pertaining to the entrepreneurs' start-up activities (Reynolds \& Curtin, 2010) and were used to map entrepreneurs' goal striving. While the PSED I data set has many positive features, it also has some less desirable features pertaining to this research. The goals (by proxies of start-up activities) considered in the PSED I data are assessed after the fact and the goals are not set by the respondents. Therefore, the second study is based on data from weekly journal entries from people in the process of launching a new venture as part of a one-year educational program. These journal entries provide data on participants' self-set goals and their behavioral outcomes; consequently, the journal entries provide more detailed, real-time data on the goal striving process. While the journal entries are limited to a one-year time frame, the PSED I data set provide data across three years.

\section{Study One: Method}

The first study utilizes publicly available archival and longitudinal data from the Panel Study of Entrepreneurial Dynamics (PSED I). The PSED I data set was chosen for two reasons. 
First, the PSED I includes data on start-up activities that people in the process of starting a new venture, entrepreneurs, engage in as part of the venture creation process (Carter, Gartner, \& Reynolds, 1996). As human behavior is determined by goals (Locke \& Latham, 1990), the past actions of entrepreneurs in the process of creating new ventures are reflections of past goalstriving behaviors and goal attainment of the PSED participants. Second, the tracking of such behaviors over a 36-month timeframe offers potential for providing a longitudinal basis for insights into entrepreneurs' goal striving as they are in the process of creating new ventures.

The PSED I was designed to identify and collect data from a nationally representative sample of entrepreneurs and from a comparison group consisting of a representative group of "typical adults" not in the process of starting a venture in the US. The sample identifica-tion procedure for the PSED I began with a telephone screening procedure. More than sixty four thousand respondents were contacted. During this initial contact, 1,261 respondents agreed and subsequently participated in a detailed telephone and mail survey. Respondents were asked, "are you, alone or with others, now trying to start a new business?" Respondents that answered this screening question affirmatively were classified as entrepreneurs $(n=830)$. Those that answered negatively were classified as members of the comparison group $(n=431)$. To focus on the participants who were actively in the process of creating new ventures from among the 1,261 participants in the PSED I meant that participants who had launched and were operating an ongoing business had to be eliminated to form the sample of entrepreneurs for this study. This also pertained to members of the comparison group. Therefore, the participants that were eliminated from consideration for this study had reported any of the three following conditions: (1) they had achieved positive cash flows from for more than 90 days at the outset of the study (6 cases; PSED item "CPHLAG"); (2) a part of their businesses in which non-person ownership 
exceeded 50\% (6 cases; PSED item "NPOWNPC"); or (3) they were members of the comparison group (431 cases; PSED item "RTYPE”). These eliminations resulted in a sample of 817 entrepreneurs used in this study.

Based on prior studies exploring start-up activities and sequences (Carter et al., 1996; Gartner, Carter, \& Reynolds, 2004), measures of behavioral outcomes, in effect goals, were identified (e.g., "Have you started any marketing or promotional efforts?") to determine if goal content changed and when goal striving took place. Appendix 1 presents a full list of these measures. Frequency counts across the initial responses, $12^{\text {th }}, 24^{\text {th }}$, and $36^{\text {th }}$ month follow-up were used to examine if systematic patterns of goal striving emerged among the entrepreneurs in their pursuit of creating a new venture.

Insert Appendix 1 about here

\section{Study One: Results}

The initial screening of the sample of 817 entrepreneurs in the PSED I data shows entrepreneurs pursue a diverse range of goals (start-up activities), with some more systematically serving as focal points than others at the outset. As shown in Table 1, financing, information and resource gathering, and communication are common focal elements during the initial phase of the start-up process. Specifically, $88.0 \%$ of the entrepreneurs reported personally investing money at the outset of the venture and $69.5 \%$ of the entrepreneurs conveyed they were actively saving money to invest in the business. Turning attention to information gathering, the data show that $85.5 \%$ of entrepreneurs had spoken with potential customers or gathered information about the competition in an effort to define the market opportunity. Nearly $71 \%$ (i.e., $70.7 \%$ ) of the 
entrepreneurs report having purchased raw materials, inventory, supplies, or components. Among what appear systematically significant though somewhat lesser frequent goals (start-up activities), nearly two thirds of entrepreneurs reported having started to communicate their venture ideas through the preparation of a business plan (60.8\%). Similarly, over half reported having initiated marketing or promotional efforts $(56.7 \%)$. Two other goals that appear significant to the majority of the entrepreneurs at this early point in the start-up process are the organization of a start-up team (56.4\%), as well as the purchase, lease or renting of major facilities, pieces of property, or equipment (50.7\%). Alternatively, a number of goals (start-up activities) suggest low importance from an overarching start-up goal standpoint. Specifically, only approximately a little more than a quarter (29.5\%) of respondents reported the devotion of full time effort toward the start-up. Less than a quarter of respondents reported the hiring of employees (14.6\%) or making contact with public assistance programs (15.3\%) or having filed for any patent, copyright, or trademark protection (13.6\%).

Insert Table 1 about here

As further shown in Table 1, financing in the form of personal investment remains strong through the first twelve months for both those reporting active start-up (8 respondents) and having achieved operating status (11 respondents), the combination representing approximately three quarters $(76 \%)$ of responses. However, such investment falls below $25 \%$ of respondents from that point on. Despite nearly $70 \%$ of the full respondent pool reporting saving money at the initial point of screening, less than $50 \%$ of respondents in either the active start-up or operating venture subsamples report doing so at the 12,24 , or 36 month follow up points. Similarly, less 
than $20 \%$ of respondents in either group reported asking for external funding. Turning attention again to information gathering, the data show that between $63.6 \%$ and $70.0 \%$ of the entrepreneurs in both the active start-up and operating business subsample had spoken with potential customers or gathered information about the competition in an effort to define the market opportunity at each follow up interview. Consistent with the results observed in the full sample, approximately $63 \%$ of the entrepreneurs reporting being in the active start-up (21) and achieving operating venture status (25) report having purchased raw materials, inventory, supplies, or components. By contrast, the proportion reverses after 12 months for both groups with only approximately $20 \%$ reporting such purchases. Again, nearly two thirds of the entrepreneurs across both sub-groups report having started to communicate their venture ideas through the preparation of a business plan at the 12-month follow up point, increasing to nearly three fourths at the 24- and 36-month follow up points. Similarly, roughly half in both groups report having initiated marketing or promotional efforts. The organization of a start-up team, as well as the purchase, lease or renting of major facilities, pieces of property, or equipment is also comparable for both groups. Alternatively, a number of goals (start-up activities) suggest similarly low importance from an overarching start-up goal standpoint with respect to respondents reporting the devotion of full time effort toward the start-up, hiring of employees, making contact with public assistance programs, or having filed for any patent, copyright, or trademark protection.

A sub-sample of entrepreneurs between the ages of 22 and 30 . Focusing on a sub-sample of entrepreneurs between the ages of 22-30 provides additional insights into the behaviors of entrepreneurs. It will also provide a basis of comparison of results with the second study. Specifically, the results presented in Table 2 provide additional insight into the patterns of 
behavior for the sub-sample of 158 entrepreneurs between the ages of 22 and 30 . Like the entire sample of 817 entrepreneurs, the entrepreneurs in the sub-sample between the ages of 22 and 30 place a disproportionate emphasis on investing their own money. Interestingly, the pattern of results suggests they do so to an even greater extent with each subsequent follow up for both those reporting being in active start-ups and having achieved operating status. Roughly $10 \%$ more individuals in this group report saving money to invest at the point of initial screening though they report saving less by a similar percentage 12 and 24 months later. The data show that a comparable $85.4 \%$ of entrepreneurs in this group had spoken with potential customers or gathered information about the competition in an effort to define the market opportunity. However, the 22-30 year old entrepreneurs tend to report gathering information at a disproportionately higher rate in subsequent follow ups, particularly for those reporting being in the active start-up stage. They also report comparable communication efforts with respect to having prepared a business plan at all reporting points. By contrast, they report buying raw materials at a disproportionately lower rate and initiating marketing or promotional efforts at approximately half the rate of the full sample. The entrepreneurs between 22 and 30 years of age at these early points in the start-up process report similar rates of organizing a start-up team and reports are consistently more frequent for those reporting being in the active start-up stage versus having achieved operating business status.

Insert Table 2 about here

The results from the entire sample of 817 entrepreneurs and the sub-sample of 158 entrepreneurs between the ages of 22 and 30 were not substantially different from the perspective 
of dynamic change in the goal striving as the start-up process progresses. Combined these results indicate a change in goal contents - the nature of the goals - among the entrepreneurs. Overall, the goal content seem to change from planning to performance across the thirty-six month period providing support for hypotheses one. The results also indicate that the entrepreneurs pursue multiple goals at any one time and these goals span across different phases in the new venture creation process providing partial support for hypotheses two.

\section{Study Two: Method}

As noted earlier, the purpose of the second study is to complement the results from the first study based on the PSED I data. Data for the second study were obtained from weekly entries in learning journals of graduate students participating in a one-year entrepreneurship program. As part of the program students, mostly in teams, sought to launch new ventures in the second half the year; from December to May. The students, in their role as entrepreneurs, were encouraged to make weekly entries in learning journals to track their progress and learning; thereby providing information on what, who, and why with respect to their goals and goal striving. These goals (start-up activities) were categorized into ten main categories and 71 subcategories. Based on the 775 journal entries and in order of frequency, the ten main categories are as follows: business planning (472), marketing (408), product development (280), organizational establishment (152), finance and investments (142), learning (112), inactivity (53), sales and offers (43), product or project change (38), and legal (32).

Journal entries from students from eight ventures enabled a fine-grained, real-time, longitudinal research design to obtain detailed insights into the goals and the goal striving process. To enhance differences between successful and not successful entrepreneurs in their goal striving, a polarized, sequential sampling approach was employed with increasing variety 
logic (Pettigrew, 1990; Eisenhardt, 1989). The sequential sample approach offer opportunity to validate the findings from each pair of cases and across industries and especially by considering a pair of cases from two different industries last shows the robustness of the findings on goal striving.

The first pair of polarized cases analyzed was two nascent ventures selling advertising on disposable items, like napkins and cups, for distribution free of charge to cafés and the like. AlfaS, a successful venture, focusing on napkins and cups set up an exclusive distribution chain; obtained high profile customers resulting in three sales during the one-year program; and was still in existence one year after incorporation. AlphaS consisted of three persons from Germany, Sweden, and the US, of which Anders, who is 30 years of age and had an educational background in marketing, is the representative. AlphaF concentrating on only cups consisted of two persons from Sweden and one person from the US. It was represented by Alfred, who is 25 and had an educational background in marketing. AlphaF was not a successful venture as the would-be entrepreneurs were unable to form any customer or stable supplier relationships.

Based on the results of the first pair of cases, the Alphas; two more polarized cases, BetaS and BetaF, were analyzed. These cases, the Betas, were based on university-based technology not yet adapted for commercial use making the main success criteria for both obtainment of external financing. BetaS was successful as the founders obtained substantial external funding for an image enhancement algorithm adapted for cellphones. BetaS consisted of three people from Canada, Poland, and the US. In this study, it was represented by Bruce, the Canadian student, who was 28 and had an educational background in business. BetaF, a not successful venture, did not obtain external financing for their indoor positioning algorithm. 
BetaF consisted of four people, three from Germany and one from the US. Ben, a German who was 25 and had an educational background in economics, represent BetaF.

Based on the results from the Alpha and Beta cases, a third pair of polarized cases, CharlieS and CharlieF, was included in the study. These two emerging ventures focused on the same target market—students studying abroad; yet, they offered different products. CharlieS offered free Cell Phone SIM cards for international students studying in Sweden and was a successful venture that obtained a distribution agreement with a large company with $\mathrm{B} \$ 12$ in sales. CharlieS consisted of Chuck from Sweden, who was 30 years of age and had industry experience, and Charles from the UK, who was 26 and had an educational background in management. CharlieF offered a student handbook for international students who wanted to study in Sweden that was based on a web-based advertising model. Not being successful in obtaining any sales meant that CharlieF was not successful. One person, Carlos, constituted CharlieF. Carlos was from Sweden, 26 years of age, had an educational background in advertising, and intended to manage the web programming and content of the site himself.

With the fourth and final pair of cases, DeltaS and DeltaF, variety among the two cases in the pair was increased by considering two ventures in different industries. DeltaS was successful in launching a new venture in food import in that it employed three full time staff. DeltaS consisted of two persons from Argentina and Sweden. Douglas, who was 30 and had an educational background in management, represented DeltaS. DeltaF was not successful at launching a child care service in that it met none of the success criteria. Dolph, 28, had an educational background in management represented DeltaF.

\section{Study Two: Results}


The Alpha Cases. While the first pair of ventures are similar in nature, marketingoriented ventures providing advertising on cups and napkins (AlphaS) and on cups only (AlphaF), they are dissimilar in their success and in their goal striving. AlphaS is customercentered. In their business plan is states: Napkins are used in public places where people are typically more receptive to advertising, for an average duration of sixteen minutes. The likelihood of being exposed to other types of advertising during this time is low. The customercentered approach of AlphaS may be due to Adam, one of the three founders and from the US, has experience in selling advertising. The founders of AlphaS started early by signing distribution deals but experienced difficulties finding suppliers that could meet their demands of low prices and fast customizable deliveries in small quantities. Early on the entrepreneurs of AlphaS set a large number of clear, small, and specific goals meaning the goals are actionable and offer clear feedback on whether the goals are attained. AlphaS continues this approach to goal striving throughout the venture creating process as shown by the founders of AlphaS make 18 journal entries and 204 set goals (an average of 11.33 goals per weekly entry).

Comparing the Alpha cases. This approach is distinctly different from the would-be entrepreneurs of AlphaF. In their business plan it is evident that there is less focus on the customer and adaption to the customer needs. The focus is what the founders want. For example, in the business plan of AlphaF it states: The business idea is to deliver environmentally friendly products [disposable paper cups], subsidized by advertisement from other companies to cafes, restaurants, and wholesalers across Sweden. No one from AlphaF have practical experience in selling advertising. They found it more challenging than they imagined finding suppliers resulting in they could not able to make their distribution chain operational. The goals of AlphaF are few and broad. In their 14 journal entries AlphaF set 19 goals (an average of 1.36 goals per 
weekly entry). In addition to the difference in number of set goals, there are also distinctions between AlphaS and AlphaF in goal setting (i.e., goal content) and goal striving. This is clear from, for example, their last journal entry in the program: in the last month of the program, May, Anders from AlphaS lists 54 discrete and specific goals for his team to pursue in the following week; while at the end of April Alfred from AlphaF lists one last broad goal for the next week: work with the business plan since it has to be handed in next week.

Comparing the Beta Cases. While there were similarities among the Beta cases, their overall goal for the venture and goal striving are distinctively different. In their business plan, the entrepreneurs of BetaS describe their business idea, and the inherent goals, as follows:

We license middleware to mobile phone and camera OEMs (original equipment manufacturers). Middleware is the software layer that lies between the operating system and the applications. Middleware is easier and cheaper to implement than hardware, but can be sold for more than standalone software. Middleware furthermore gives our customers flexibility to customize our technology to meet their platform requirements through an open API (application programing interface).

The entrepreneurs of BetaS develop a product offering based on bisociation (Ko, 2004), a result of inter-departmental research and knowledge, among biology and mathematics. The founders network intensively and set a high number of clear, small, specific, and actionable goals. They make 17 journal entries with a total of 95 goals (an average of 5.59 goals per weekly entry) that provide clear feedback on the goal striving towards the overall goals of BetaS. For example, early on these entrepreneurs are successful in business plan competitions that also 
confirm their market potential. This is also evident in Bill from BetaS networking with several high profile industry actors, including Sony and Samsung.

In contrast, the goals of BetaF were vague, that is the goals lack specificity. For example, their overall goal, per their business idea, is described in their business plan as follows:

Through licensing agreements with chip manufacturers and strategic partnership with Original Equipment Manufacturers (OEMs - here: Mobile Phone Manufacturers) and Carrier Service Providers (CSPS), TrackIT will work towards having the algorithm embedded into mobile phones.

Also unlike BetaS, the entrepreneurs of BetaF are not successful in business plan competitions despite backing from a university research team; nor do they get leads similar to those of BetaS through networking. The venture team of BetaF sets a limited number of goals. They set 29 goals in their 19 journal entries; an average of 1.53 goals per weekly entry.

Comparing the Alpha and Beta Cases. When the successful ventures, AlphaS and BetaS, are compared, it becomes evident why they are successful. Both venture teams set a large number of clear, small, specific, and actionable goals that provide clear feedback on their goal striving towards the overall goal of a successful venture creation. They start setting clear, small, specific, and actionable goals early in the venture creation process and pursue multiple goals simultaneously. For example, Bruce of BetaS lists the following eight goals in his second journal entry:

Get five sample dark videos from different sources (iPhone, point and shoot camera, professional camera etc.) and with different compressions to test the algorithm; brainstorm names and website domains for the company; work on the company logo; get in contact with a programmer who can perform the algorithm 
update and asses the cost; launch a Google ad word campaign to test the demand in the market for our technology.

This approach of pursuing multiple small, specific, and actionable goals simultaneously is continued throughout the venture creation process. At the risk of repetition, Anders from AlphaS lists 54 small, specific, and actionable goals for the venture team to pursue in the following week in his last weekly journal entry.

In contrast, the pattern of goal setting and striving of the not successful venture teams, AlphaF and BetaF, is different from the successful entrepreneurs. The not successful venture teams list few goals in their weekly journal entries and these goals are vague in nature, lack specificity. For example, Alfred of AlphaF in his second weekly journal entry lists the two following goals: "we hope to get approval for our business from our program coordinator and also set up a series of goals that we would like to accomplish in the month of December" and Ben from BetaF lists one goal in his last weekly journal entry, which states: work with the business plan since it has to be handed in next week.

Comparing the Charlie Cases. This pair of cases further evidences the patterns found in and between the Alpha and Beta cases. In the successful venture, CharlieS, the two founders set many clear, small, specific, and actionable goals that offer clear feedback whether a goal is attained in the pursuit of the overall goal described in their business plan:

One of the first services provided through CharlieS will be a no obligation, free, prepay SIM Card for the students study abroad destination, which the student will receive in their home country. The prepay nature of this SIM card means the student has complete control over spending and the length of time they choose to stay with that network. 
As part of their goal striving, the founders of CharlieS start setting clear, small, specific, and actionable goals early on and keep setting such goals throughout the venture creation process. For example, in his first journal entry, Charles (from the UK) sets the following three goals: further work with MHBC to improve pitch to industrial partners; finalize branding; and meet with legal person to create a 'signable' contract between us and future Universities. Whereas, in the not successful venture of CharlieF, the set goals are vague and focused on the entrepreneur, Carlos, rather than on customer needs or the venture creation. Taken from Carlos' business plan, the overall goal of CharlieF was as follows:

By combining the unique knowledge of the initiator of this venture, gained from his own crisscrossing academic career abroad, and the power of online marketing will open a new segment in which how to create, distribute and consume products for the study abroad niche.

Also, Carlos only sets one goal, which is vague and focused on Carlos, for the following week in his first journal entry. It is as follows:

I got my mentor yesterday so I will contact him and see if I perhaps can get a meeting and find out if he has any insights on how to make a lot of money on the internet $\odot$ (or in general). In terms of business development not much is likely to happen next week due to the assignment that has to be written for BUSM63, but I will aim write one or two chapters.

Comparing the Charlie cases reveal that the entrepreneurs in both cases set a similar number of goals - the founders of CharlieS set 43 goals in 17 journal entries, an average of 2.43 goals per entry, and Carlos of CharlieF sets 42 goals in 18 journal entries, an average of 2.33 per journal entry. While the distinction between CharlieS and CharlieF is not the quantity of goals, 
the distinction is in the goal dimensions (i.e., goal content, goal specificity). Unlike the goals of CharlieF, the goals of CharlieS are clear, small, specific, and actionable. This means that the two founders of CharlieS are more aware of what needs to be done and whether a particular goal is accomplished. The comparison of the Charlie cases clear illustrated that the goals need to be context specific relation to the overall goal being pursued in the goal striving process.

The Delta Cases. Even though DeltaS and DeltaF are in different industries and focus on different customers, the patterns in their goal striving are similar to the cases previously considered. The founders of DeltaS set multiple clear, small, specific, and actionable goals that provide clear feedback on whether a goal is attained; while the founder of DeltaF, Dolph, sets few (and at times no goals) that lack clarity and specificity making it difficult to pursue and to obtain feedback on regarding goal attainment. The entrepreneurs creating DeltaS set 55 goals in 15 journal entries (an average of 3.67 goals per journal entry); while Dolph of DeltaF sets a total of 16 goals in 13 journal entries (an average of 1.23 goals per journal entry). Furthermore, Dolph sets no goals in his first week of the program but lists two meetings in his first journal entry in the second week. The agenda for both of these meetings is ambiguous as this journal entry shows: My first work next week will be setting a meeting with AF and then I'll see the possibilities what they can do for me, then I'll have another meeting with international office to be able to have my table in AF on information market. On the other hand, Douglass of DeltaS lists multiple clear, small, specific, and actionable goals in his first journal entry in the first week of the program. He writes:

Meeting with Tetra Pak designers on Saturday the 3rd of December 2011. Brand logo, image, product image, packaging and label design and development. 
Meeting via Skype with "CS Creaciones", Argentine web page designing and development firm, on Tuesday the 6th of December 2011. Start working on developing the web page of my firm. By hiring an Argentine S\&ME firm, I will save up to 55\% in the design and development of the web site.

Meeting with Mrs. Benedict on Tuesday 6th 2011 at 15:45pm at Ideon Agora. Discuss the market for my product and best strategies to launch it successfully.

Findings from All Eight Cases. While the entrepreneurs differed with respect to goal setting, goal striving, and goal attainment, the journal entries shows that they all experienced frustrations with start-up activities and shifted from planning-oriented goals towards performance-oriented goals pertaining to financing and sales as the venture creation progressed. Similar to the results from study one, these results provide support for hypothesis one.

There are two clear patterns in entrepreneurs' goal striving that are evident from the eight cases from across multiple industries indicating that these two patterns are robust. The eight cases show there are a distinct pattern in the goal striving of successful venture teams and an equally distinct pattern in the goal striving of not successful would-be entrepreneurs. The not successful entrepreneurs do not set goals that can assist them in pursuing the overall goal of new venture creation. The set goals are few and may be characterized as vague or lacking clarity meaning that the goals to not facilitate action or clear feedback on goal attainment. Also, these goals seem to lack focus on the venture, e.g., customers, networking. On the other hand, goal striving of successful entrepreneurs is characterized by these entrepreneurs set multiple context specific goals that (1) focused on the ventures and its' development, (2) are clear, small, specific, and actionable, and (3) are pursued simultaneously. Equally important is that these goals hold 
potential for clear feedback on whether a goal is attained and offer the entrepreneurs opportunity to pursue multiple goals simultaneously. These results provide support for hypotheses two.

\section{DISCUSSION}

The purpose of this research is to examine entrepreneurs' goal striving in the process of creating new ventures. The reason for examining entrepreneurs' goal striving is to shed light on entrepreneurs' behavior. Scholars have observed that most motivation theories are simplistic and static meaning there is a need for more complex and dynamic motivation models to explain people's behavior (Steers et al., 2004). Entrepreneurs' behavior is an overlooked area in entrepreneurship research (Bird \& Schjoedt, 2009; Bird, Schjoedt, \& Baum, 2012). While goals are at the center of most, if not all, motivation theories-goal setting theory (Locke \& Latham, 1990, 2004) is also a simplistic and static motivation theory, the other main aspect that can explain people's behavior is goal striving (James, 1890; Gollwitzer, 1990). A model of goal striving was developed based, primarily, on the hierarchy of goals (Powers, 1973, 205) and control theory (Carver \& Scheier, 1990, 1998; Vallacher \& Wegner, 1987, 2012). This goal striving model explains people's behavior based on people seek to minimize or eliminate the discrepancy between their current situation and a goal - a desirable situation from a behavioral outcome (Locke \& Latham, 1990). It further explains how successful people break a large goal into multiple smaller goals upon which they can take action and obtain feedback on whether the discrepancy has been reduced or eliminated (goal attainment). As such the goal striving model presented and examined in this research meets the call for more complex and dynamic motivation models to explain people's behavior (Steers et al., 2004) and provide insights into entrepreneurs' behavior as they undertake venture creation. 
The results from two studies using panel data and weekly journal entries from an education program in entrepreneurs centered on new venture creation as part of the program provide strong support for entrepreneurs' goal striving (and for the two hypotheses). The results show that the nature of their entrepreneurs' goals (i.e., goal content) change as the goals are attained and as the entrepreneurs progress with the new venture creation. The results evidence two clear patterns in the goal striving. Successful entrepreneurs break larger goals into multiple smaller goals that are focused on the venture, that are clear and actionable, and that offer clear feedback on whether the goal is attained. Another feature is that the successful entrepreneurs pursue multiple goals simultaneously. On the other hand, the not successful entrepreneurs set fewer goals and their goals are vague, lack clarity; are less actionable; and offer less potential for clear feedback on goal attainment. Also, several of the goals of the not successful would-be entrepreneurs did not focus on the venture but focused on the entrepreneurs per se; in effect the goals were not context specific. Two such distinct patterns between successful and not successful entrepreneurs in their goal striving provide novel insights into entrepreneurs' behavior and into how and why some entrepreneurs are successful.

These insights into entrepreneurs' goal striving and, in effect, behavior move beyond conceptual models that account for entrepreneurs' intentions and, in turn, behavior - e.g., the theory of planned behavior (Ajzen, 1991) - that are widely examined in the entrepreneurship literature but have shown limited efficiency in explaining intentions and behavior (Armitage \& Conner, 2001; Schlaegel \& Koenig, 2014). For example, Kolvereid (1996) found that many of the study participants had entrepreneurial intentions; yet, few became self-employed. One key difference between research focusing on intentions and the focus on goal striving in this research is the proximity to behavior between intentions and goals. Intention studies in entrepreneurs 
either seek to explain the genesis of entrepreneurial intentions (e.g., Boyd \& Vozikis, 1994) or associate entrepreneurial intentions with outcomes such as new venture creation or venture performance (e.g., Zhao, Seibert, \& Lumpkin, 2010). This means the association between intentions and intermediate behavioral outcomes is not examined or accounted for in the research. In very few intention studies, the researchers acknowledge that between entrepreneurial intentions and outcome there is another set of intentions that need to be considered; that is, intentions to try (Brännback, Krueger, Carsrud, \& Elfving, 2007) or implementation intentions (Gollwitzer \& Schaal, 1998). The marketing literature has examined intentions for an extended period. Marketing researchers have shown that intentions to try mediate intentions (e.g., Bagozzi \& Warshaw, 1990) and have further extended intention models to include goal-directed behavior and the hierarchy of goals (e.g., Bay \& Daniel, 2003) that form the basis for the goal striving model examined in this research. This shows that while goals per se and intentions are related but distinct constructs, this study on entrepreneurs' goal striving goes beyond research on intentions in the entrepreneurship literature by closing the link between goals and behavioral outcomes. Consisting with research in the management literature based on the goal striving model based on the hierarchy of goals (powers, 1973, 2005) and control theory (Carver \& Scheier, 1990, 1998; Vancouver, 2005; Vallacher \& Wegner, 1987, 2012) has potential to explain job search activity and, in turn, career choice better than career intention research (e.g., Liu, Wang, Liao, \& Shi, 2014).

The strengths of this include the use of longitudinal panel data and longitudinal rich realtime data from week journal entries from people in the process of creation new ventures. Yet, these data sources also had some limitations. The goals considered from the panel data were inferred from start-up activities that were chosen for inclusion in the panel study by researchers. 
Thus, these goals were not self-set. The goals examined form the weekly journal entries were self-set goals and set in real-time. Unlike the panel data, the entrepreneurs providing the journal entries represent a focused sample despite there were participants from multiple countries and with various education background yet all college educated. Also, the limited time available for the program participants, from December to May, is a limited time frame and maybe too limited.

Future research could examine the goal striving model presented in this research on less focused samples and compare goal striving of entrepreneurs, self-employed who have not created their own venture, managers and other organizationally employed persons. Also, future research could compare longitudinal panel data on goals (start-up activities) across nations using data from the Global Entrepreneurship Monitors, for example. In addition to journal entries, future research could also be based on rich data from interviews with or autobiographies from entrepreneurs at the risk of retrospective and social desirability bias. Also, direct or participant observation hold potential for rich data on goal striving. While participant observation may inform of goals set, direct observation may have to be supplemented with considerations with the observed entrepreneurs to determine the goals to avoid having to infer the goals set. The goal striving model could be expanded by including self-efficacy, passion and tenacity. Self-efficacy could be assessed prior to and on an interval basis throughout the goal striving to examine if selfefficacy is an antecedent or and outcome of goal striving and goal attainment as suggested in Social Learning Theory (Bandura, 1982, 1997).

\section{CONCLUSION}

The findings illustrate that successful entrepreneurs pursue multiple smaller, specific, and actionable goals simultaneously that provide feedback on goal attainment in their goal striving towards new venture creation. It also provides support for the goal striving process is based on a 
hierarchy of goal (Powers, 1973, 2005) and feedback control (Carver \& Scheier, 1990, 1998; Vancouver, 2005; Vallacher \& Wegner, 1987, 2012). Collectively, the findings of this research elucidate entrepreneurs' behavior; specifically how and why entrepreneurs behave differently and take different paths in the new venture creation process. In doing so this research also provides an explanation of why some entrepreneurs are successful while others are not in creating new ventures; an issue driving entrepreneurship research. Consequently, this research advances the entrepreneurship literature and our understanding of entrepreneurs' behavior by showing how successful entrepreneurs' goal striving is characterized by breaking goals into a large number of smaller, more specific, and actionable goals that are pursued simultaneously and provide feedback on goal attainment. 


\section{REFERENCES}

Armitage, C. J. \& Conner, M. (2001). Efficacy of the theory of planned behavior: attitudes, intentions, and review. British Journal of Social Psychology, 40, 471-499.

Austin, J. T., \& Vancouver, J. B. (1996). Goal constructs in psychology: Structure, process, and content. Psychological Bulletin, 120(3), 338-375.

Ajzen, I. (1991). Theory of planned behavior: Some unresolved issues. Organizational Behavior and Human Decision Processes, 50(2), 179-21.

Bagozzi, R. \& Warshaw, P. (1990.) Trying to consume. Journal of Consumer Research, 17(2), 127-140.

Bandura, A. (1997). Self-efficacy: The exercise of control. New York: W. H. Freeman.

Bandura, A. (1982). Self-efficacy mechanism in human agency. American Psychologist, 37, 122147.

Bay, D. \& Daniel, H. (2003). The theory of trying \& goal-directed behavior: The effect of moving up the hierarchy of goals. Psychology \& Marketing, 20(8), 669-684.

Bird, B. J. (1989). Entrepreneurial Behavior. Glenview, IL: Scott, Foresman, and Company.

Bird, B. \& Schjoedt, L. (2009). Entrepreneurial Behavior: Its nature, scope, recent research and future research. In A. L. Carsrud \& M. E. Brännback (Eds.), Understanding the Entrepreneurial Mind: Opening the Black Box (pp. 327-358). Springer AG.

Bird, B. J., Schjoedt, L. \& Baum, J. R. (2012). Entrepreneurs' behavior: elucidation and measurement. Entrepreneurship Theory and Practice, 36(5), 889-913.

Boyd, N. G., \& Vozikis, G. S. (1994). The influence of self-efficacy on the development of entrepreneurial intentions and actions. Entrepreneurship theory and practice, 18, 63-63.

Brännback, M., Krueger, N., Carsrud, A., \& Elfving, J. (2007). "Trying” to be an entrepreneur? A "goal-specific" challenge to the intentions model. Paper presented at the Babson College Entrepreneurship Research Conference, Madrid, Spain.

Carter, N. M., Gartner, W. B., \& Reynolds, P. D. (1996). Exploring start-up events sequences. Journal of Business Venturing, 11, 151-166.

Carver, C. S. \& Scheier, M. F. (1998). On the self-regulation of behavior. New York, NY: Cambridge University Press.

Carver, C. S. \& Scheier, M. F. (1990). Principles of self-regulation: Action and emotion. In E. T. Higgins \& R. M. Sorrentino (Eds.), Handbook of motivation and cognition: Foundations of social behavior (Vol. 2, pp. 3-52). New York: Guilford Press. 
Dunkelberg, W., More, C., Scott, J., \& Stull, W. (2013). Do entrepreneurial goals matter?

Resource allocation in new owner-manager firms. Journal of Business Venturing, 28, 225-240.

Eisenhardt, K. M. (1989). Building theories from case study research. Academy of Management Review, 14(4), 532-550.

Gartner, W. B. (1988). "Who is an entrepreneur?" Is the wrong question. American Journal of Small Business, 12, 11-32.

Gartner, W. B., Carter, N. M. \& Reynolds, P. D. (2004). Business start-up activities. In W. B. Gartner, K. G. Shaver, N. M. Carter, and P. D. Reynolds (Eds.), Handbook of Entrepreneurial Dynamics: The process of business creation (pp. 285-298). Thousand Oaks, CA: Sage.

Gartner, W. B., Shaver, K. G., Carter, N. M., \& Reynolds, P. D. (2004). Handbook of Entrepreneurial Dynamics: The process of business creation. Thousand Oaks, CA: Sage.

Gollwitzer, P. M. (1990). Action phases and mind-sets. In E. T. Higgins \& R. M. Sorrentino (Eds.), The handbook of motivation and cognition: Foundations of social behavior (Vol. 2, pp. 53-92). New York: Guilford Press.

Gollwitzer, P. M. \& Schaal, B. (1998). Metacognition in action: The importance of implementation intentions. Personality and Social Psychology Review, 2(2), 124-136.

Higgins, E. T. (1997). Beyond pleasure and pain. American Psychologist, 52, 1280-1300.

Higgins, E. T. (1987). Self-discrepancy: a theory relating self and affect. Psychological Review, 94(3), 319-340.

James, W. (1890). The principles of psychology. New York: Henry Holt \& Co.

Ko, S. (2004). Bisociation and opportunity. In J. E. Butler (Ed.), Opportunity Identification and Entrepreneurial Behavior (pp. 99-114). Information Age Publishing.

Klein, H. I. \& Kim, I. S. 1998. A field study of the influence of situational constraints, leadermember exchange, and goal commitment on performance. Academy of Management Journal, 41, 88-95.

Kolvereid, L. (1996). Organizational employment versus self-employment: Reasons for career choice intentions. Entrepreneurship: Theory and Practice, 21, 23-31.

Krueger, N. F., \& Brazeal, D. V. (1994). Entrepreneurial potential and potential entrepreneurs. Entrepreneurship Theory and Practice, 18, 91-104. 
Liu, S., Wang, M., Liao, H., \& Shi, J. (2014). Self-regulation during job search: the opposing effects of employment self-efficacy and job search behavior self-efficacy: Journal of Applied Psychology, 99(6), 1159-1172.

Locke, E. A., \& Latham, G. P. (2004). What should we do about motivation theory? Six recommendations for the twenty-first century. Academy of Management Review, 29(3), 388-403.

Locke, E. A., \& Latham, G. P. (1990). A theory of goal setting and task performance. Englewood Cliffs, NJ: Prentice Hall.

Locke, E. A., Shaw, K. N., Saari, L. M. \& Latham, G. P. (1981). Goal setting and task performance: 1969-1980. Psychological Bulletin, 90, 125-152.

Mitchell, T. R. (1997). Matching motivational strategies with organizational contexts. Research in Organizational Behavior, 19, 57-94.

Naffziger, D., Hornsby, J. S., \& Kuratko, D. F. (1994). A proposed research model of entrepreneurial motivation. Entrepreneurship Theory and Practice, 18(3), 29-39.

Naylor, J. C. \& Ilgen, D. I. (1984). Goal-setting: A theoretical analysis of a motivational technology, in B. M. Staw \& L. L. Cummings (Eds.), Research in organizational behavior, (pp. 95-140). Greenwich, CT: JAI Press.

Pettigrew, A. M. (1990). Longitudinal field research on change: theory and practice. Organization science, 1(3), 267-292.

Powers, W. T. (2005). Behaviour: The control of perception, 2nd edition New Canaan, CT: Benchmark Publications.

Powers, W. T. (1973). Behavior: the control of perception. New York, NY: Aldine de Gruyter.

Reynolds, P. D., \& Curtin, R. T. (Eds.). (2010). New business creation: An international overview (Vol. 27). Springer Science \& Business Media.

Reynolds, P. D. (2010). New firm creation in the United States: A PSED I overview. Foundations and Trends in Entrepreneurship, 3(1).

Sagie, A. 1996. Effects of leader's communication style and participative goal setting on performance and attitudes. Human Performance, 9, 51-64.

Schlaegel, C. \& Koenig, M. (2014). Determinants of entrepreneurial intent: a meta-analytic test and integration of competing models. Entrepreneurship: Theory \& Practice, 38(2), 291 332 
Shane, S., Locke, E. A., \& Collins, C. J. (2003). Entrepreneurial motivation. Human Resource Management Review, 13, 257-279.

Shane, S. \&Venkataraman, S. (2000). The promise of entrepreneurship as a field of research. Academy of Management Review, 25(1): 217-226.

Steers, R. M., Mowday, R. T., \& Shapiro, D. L. (2004). Introduction to special topic forum the future of work motivation theory: Academy of Management Review, 29(3), 379-387.

Stevenson, H. H., Roberts, M. J., \& Grousbeck, H. I. (1985). New Business Ventures and the Entrepreneur. Burr Ridge, IL: Richard D. Irwin.

Vancouver, J. (2005). The depth of history and explanation as benefit and bane for psychological control theories. Journal of Applied Psychology, 90, 38-52.

Vallacher, R. R., \& Wegner, D. M. (2012). Action identification theory: The highs and lows of personal agency. In P. Van Lange, A. W. Kruglanski, \& E. T. Higgins (Eds.), Handbook of theories in social psychology (pp. 327-348). London: Sage.

Vallacher, R. R., \& Wegner, D. M. (1987). What do people think they're doing? Action identification and human behavior: Psychological Review, 94(1), 3-15.

Vroom, J. P. (1964). Work and motivation. New York: Wiley.

Zhao, H., Seibert, S. E., \& Lumpkin, G. T. (2010). The relationship of personality to entrepreneurial intentions and performance: A meta-analytic review. Journal of management, 36(2), 381-404. 


\section{Appendix 1: List of Start-up Behaviors Identified in PSED}

\begin{tabular}{|c|c|c|}
\hline Item & Start-up Activity & Question text \\
\hline Q116 & Organized team & $\begin{array}{l}\text { Has a start-up team been organized? (A start-up team is more than one person that helps to put the firm } \\
\text { in place, expecting to share ownership. If both married partners own and operate a business, that is a } \\
\text { start-up team.) }\end{array}$ \\
\hline Q111 & Prepared business plan & Have you prepared a business plan? \\
\hline Q131 & $\begin{array}{l}\text { Bought facilities / } \\
\text { equipment }\end{array}$ & $\begin{array}{l}\text { Have any major items like equipment, facilities, or property been purchased, leased, or rented for the } \\
\text { new (start-up/business)? }\end{array}$ \\
\hline Q143 & Invested own money & Have you invested any of your own money in this business? \\
\hline Q145 & Asked for funding & Have financial institutions or other people been asked for funds? \\
\hline Q153 & Devoted full time & Have you begun to devote full time to the business, that is 35 or more hours per week? \\
\hline Q124 & Patent/copyright & Have you applied for a patent, copyright or trademark relevant to this new business been submitted? \\
\hline Q155 & Hired employees & Have any employees or managers been hired for pay - workers that would NOT share ownership? \\
\hline Q139 & Saved money & Are you now saving money to invest in this business? \\
\hline Q160 & Banking account & Has a bank account been opened exclusively for this new business? \\
\hline Q171 & Contact information & $\begin{array}{l}\text { Does the new business have its own listing in the phone book? [Enter "Yes", if no phone listing because } \\
\text { it is only an internet business.] }\end{array}$ \\
\hline Q122 & Marketing & Have you started any marketing or promotional efforts? \\
\hline Q128 & Raw material & $\begin{array}{l}\text { Have any raw materials, inventory, supplies, or components for the new (start-up/business) been } \\
\text { purchased? }\end{array}$ \\
\hline Q134 & Gathering information & $\begin{array}{l}\text { Has an effort been made to define the market opportunities by talking with potential customers or getting } \\
\text { information about the competition? }\end{array}$ \\
\hline Q303 & $\begin{array}{l}\text { Contact assistance } \\
\text { program }\end{array}$ & $\begin{array}{l}\text { Many programs to help new businesses get established have been developed. Federal, state, and local } \\
\text { governments, universities, and voluntary associations sponsor them. Have you made contact with any } \\
\text { such program? }\end{array}$ \\
\hline Q175 & Legal form & Has the business paid any state unemployment insurance taxes? \\
\hline Q177 & Legal form & Has the new business paid any federal social security taxes, sometimes called FICA payments? \\
\hline Q179 & Legal form & Has the new business filed a federal income tax return? \\
\hline
\end{tabular}


Table 1: Start-up Activities Reported Complete by Nascent Entrepreneurs across Waves and by Venture Status (Active Start-up Vs. Operating Business)

\begin{tabular}{|c|c|c|c|c|c|c|c|c|c|c|c|c|c|c|c|c|c|c|c|c|c|c|c|c|c|c|c|c|c|c|c|c|}
\hline \multirow{3}{*}{ Start-up Activity } & \multicolumn{5}{|c|}{ Initial Screen } & \multicolumn{9}{|c|}{ 12-Month Follow Up } & \multicolumn{9}{|c|}{ 24-Month Follow Up } & \multicolumn{9}{|c|}{ 36-Month Follow Up } \\
\hline & \multirow[b]{2}{*}{$\begin{array}{c}\text { PSED } \\
\text { Item }\end{array}$} & \multirow[b]{2}{*}{ Yes } & \multirow[b]{2}{*}{$\%$} & \multirow[b]{2}{*}{ No } & \multirow[b]{2}{*}{$\%$} & \multirow[b]{2}{*}{$\begin{array}{c}\text { PSED } \\
\text { Item }\end{array}$} & \multicolumn{3}{|c|}{ Yes } & \multirow[t]{2}{*}{$\%$} & \multicolumn{3}{|c|}{ No } & \multirow[t]{2}{*}{$\%$} & \multirow[b]{2}{*}{$\begin{array}{c}\text { PSED } \\
\text { Item }\end{array}$} & \multicolumn{3}{|c|}{ Yes } & \multirow[t]{2}{*}{$\%$} & \multicolumn{3}{|c|}{ No } & \multirow[t]{2}{*}{$\%$} & \multirow[b]{2}{*}{$\begin{array}{l}\text { PSED } \\
\text { Item }\end{array}$} & \multicolumn{3}{|c|}{ Yes } & $\%$ & & No & & $\%$ \\
\hline & & & & & & & $\begin{array}{c}\text { Full } \\
\text { sample }\end{array}$ & $\begin{array}{l}\text { Act. } \\
\text { S-up }\end{array}$ & $\begin{array}{c}\text { Oper. } \\
\text { Bus. }\end{array}$ & & $\begin{array}{c}\text { Full } \\
\text { sample }\end{array}$ & $\begin{array}{l}\text { Act. } \\
\text { S-up }\end{array}$ & $\begin{array}{l}\text { Oper. } \\
\text { Bus. }\end{array}$ & & & $\begin{array}{c}\text { Full } \\
\text { sample }\end{array}$ & $\begin{array}{l}\text { Act. } \\
\text { S-up }\end{array}$ & $\begin{array}{c}\text { Oper. } \\
\text { Bus. }\end{array}$ & & $\begin{array}{c}\text { Full } \\
\text { sample }\end{array}$ & $\begin{array}{l}\text { Act. } \\
\text { S-up }\end{array}$ & $\begin{array}{c}\text { Oper. } \\
\text { Bus. }\end{array}$ & & & $\begin{array}{c}\text { Full } \\
\text { sample }\end{array}$ & $\begin{array}{l}\text { Act. } \\
\text { S-up }\end{array}$ & $\begin{array}{c}\text { Oper. } \\
\text { Bus. }\end{array}$ & & $\begin{array}{c}\text { Full } \\
\text { sample }\end{array}$ & $\begin{array}{l}\text { Act. } \\
\text { S-up }\end{array}$ & $\begin{array}{c}\text { Oper. } \\
\text { Bus. }\end{array}$ & \\
\hline Organized team & Q116 & 460 & $56.4 \%$ & 355 & $43.6 \%$ & R573 & 37 & 20 & 17 & $25.3 \%$ & 111 & 57 & 52 & $74.7 \%$ & S573 & 24 & 11 & 1 & $22.6 \%$ & 91 & 20 & 21 & $77.4 \%$ & T573 & 44 & 4 & 5 & $33.3 \%$ & 143 & 13 & 5 & $66.7 \%$ \\
\hline Prepared business plan & Q111 & 495 & $60.8 \%$ & 319 & $39.2 \%$ & R568 & 199 & 111 & 85 & $57.8 \%$ & 145 & 63 & 80 & $42.2 \%$ & S568 & 231 & 59 & 52 & $81.0 \%$ & 68 & 17 & 9 & $19.0 \%$ & T568 & 312 & 26 & 20 & $73.0 \%$ & 128 & 6 & 11 & $27.0 \%$ \\
\hline Bought facilities / equipment & Q131 & 413 & $50.7 \%$ & 402 & $49.3 \%$ & R588 & 61 & 35 & 25 & $46.2 \%$ & 70 & 49 & 21 & $53.8 \%$ & S588 & 33 & 6 & 8 & $34.1 \%$ & 55 & 18 & 9 & $65.9 \%$ & T588 & 59 & 5 & 4 & $42.9 \%$ & 112 & 7 & 5 & $57.1 \%$ \\
\hline Invested own money & Q143 & 718 & $88.0 \%$ & 98 & $12.0 \%$ & R600 & 19 & 8 & 11 & $76.0 \%$ & 6 & 4 & 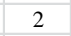 & $24.0 \%$ & S600 & 14 & 2 & 6 & $10.7 \%$ & 6 & 1 & 66 & $89.3 \%$ & $\mathrm{~T} 600$ & 31 & 3 & 2 & $7.9 \%$ & 10 & 29 & 29 & $92.1 \%$ \\
\hline Asked for funding & Q145 & 173 & $21.3 \%$ & 639 & $78.7 \%$ & R602 & 41 & 22 & 19 & $15.8 \%$ & 221 & 118 & 101 & $84.2 \%$ & S602 & 33 & 10 & 6 & $16.7 \%$ & 174 & 43 & 37 & $83.3 \%$ & T602 & 45 & 5 & 3 & $18.6 \%$ & 269 & 18 & 17 & $81.4 \%$ \\
\hline Devoted full time & Q153 & 241 & $29.5 \%$ & 575 & $70.5 \%$ & R610 & 57 & 29 & 27 & $25.9 \%$ & 161 & 96 & 64 & $74.1 \%$ & S610 & 31 & 5 & 12 & $23.3 \%$ & 123 & 40 & 16 & $76.7 \%$ & T610 & 52 & 2 & 4 & $16.7 \%$ & 206 & 17 & 13 & $83.3 \%$ \\
\hline Patent/copyright & Q124 & 110 & $13.6 \%$ & 698 & $86.4 \%$ & R581 & 23 & 12 & 11 & $8.3 \%$ & 260 & 128 & 127 & $91.7 \%$ & S581 & 11 & 2 & 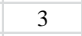 & $5.1 \%$ & 213 & 52 & 41 & $94.9 \%$ & T581 & 25 & 2 & 2 & $7.8 \%$ & 323 & 20 & 27 & $92.2 \%$ \\
\hline Hired employees & Q155 & 119 & $14.6 \%$ & 696 & $85.4 \%$ & R612 & 49 & 21 & 28 & $17.7 \%$ & 232 & 129 & 99 & $82.3 \%$ & S612 & 40 & 4 & 14 & $17.1 \%$ & 180 & 57 & 30 & $82.9 \%$ & T612 & 39 & 2 & 6 & $15.7 \%$ & 307 & 24 & 19 & $84.3 \%$ \\
\hline Saved money & 39 & 567 & $69.6 \%$ & 248 & $30.4 \%$ & 6 & 41 & 21 & 19 & $7.4 \%$ & 68 & 23 & 44 & $62.6 \%$ & S596 & 17 & 3 & 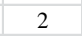 & $25.0 \%$ & 46 & 8 & 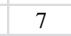 & $75.0 \%$ & T596 & 43 & 5 & 2 & $46.7 \%$ & 74 & 2 & 6 & $53.3 \%$ \\
\hline Banking account & Q160 & 281 & $35.0 \%$ & 522 & $65.0 \%$ & R617 & 65 & 24 & 40 & $33.3 \%$ & 130 & 92 & 36 & $66.7 \%$ & S617 & 65 & 7 & 9 & $24.6 \%$ & 130 & 27 & 22 & $75.4 \%$ & T617 & 79 & 0 & 8 & $36.8 \%$ & 157 & 13 & 11 & $63.2 \%$ \\
\hline Contact informatic & Q171 & 137 & $17.0 \%$ & 669 & $83.0 \%$ & R629 & 43 & 15 & 28 & $16.3 \%$ & 224 & 137 & 83 & $83.7 \%$ & S629 & & 4 & 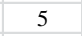 & $8.2 \%$ & 190 & 65 & 36 & $91.8 \%$ & T629 & 57 & 1 & 7 & $14.0 \%$ & 277 & 30 & 19 & $86.0 \%$ \\
\hline Marketing & Q122 & 463 & $56.7 \%$ & 353 & $43.3 \%$ & R579 & 63 & 34 & 29 & $55.3 \%$ & 52 & 33 & 18 & $44.7 \%$ & S579 & 33 & 8 & 8 & $45.7 \%$ & 41 & 11 & 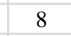 & $54.3 \%$ & T579 & 63 & 3 & 7 & $50.0 \%$ & 76 & 8 & 2 & $50.0 \%$ \\
\hline Raw material & Q128 & 577 & $70.7 \%$ & 239 & $29.3 \%$ & R585 & 46 & 21 & 25 & $.0 \%$ & 27 & 17 & 10 & $37.0 \%$ & S585 & 2 & 8 & 7 & $17.0 \%$ & 28 & 8 & 65 & $83.0 \%$ & T585 & 46 & 5 & 3 & $21.6 \%$ & 49 & 27 & 2 & $78.4 \%$ \\
\hline Gather & 134 & 698 & $85.5 \%$ & 118 & $14.5 \%$ & R591 & 27 & 19 & 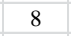 & $\%$ & 12 & 5 & 7 & $30.8 \%$ & S591 & $\pi$ & 3 & 4 & $63.6 \%$ & 8 & 2 & 2 & $36.4 \%$ & T591 & 36 & 4 & 3 & $70.0 \%$ & 19 & 1 & 2 & $30.0 \%$ \\
\hline Contact assistance program & Q303 & 123 & $15.3 \%$ & 683 & $84.7 \%$ & R755 & 46 & 24 & 20 & $16.0 \%$ & 233 & 120 & 111 & $84.0 \%$ & S755 & 45 & 12 & 12 & $20.3 \%$ & 184 & 50 & 44 & $79.7 \%$ & $\mathrm{~T} 755$ & 34 & 4 & 2 & $12.0 \%$ & 166 & 23 & 21 & $88.0 \%$ \\
\hline Legal form & 175 & 65 & $8.1 \%$ & 734 & $91.9 \%$ & R633 & 30 & 8 & 22 & $9.9 \%$ & 279 & 152 & 122 & $90.1 \%$ & S633 & 3 & 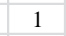 & 1 & $10.9 \%$ & 219 & 67 & 39 & $0.1 / 0$ & T633 & 49 & 27 & J & $50.8 \%$ & 330 & 5 & 24 & $49.2 \%$ \\
\hline Legal form & Q177 & 98 & $12.3 \%$ & 700 & $87.7 \%$ & R635 & 56 & 16 & 40 & $19.6 \%$ & 234 & 141 & 89 & $80.4 \%$ & S635 & 45 & 4 & 16 & $19.2 \%$ & 166 & 56 & 28 & $80.8 \%$ & T635 & 68 & 24 & 6 & $54.5 \%$ & 267 & 8 & 17 & $45.5 \%$ \\
\hline Legal form & Q179 & 137 & $17.0 \%$ & 668 & $83.0 \%$ & R637 & 83 & 30 & 53 & $31.9 \%$ & 180 & 115 & 62 & $68.1 \%$ & S637 & 65 & 10 & 16 & $31.0 \%$ & 107 & 45 & 13 & $69.0 \%$ & T637 & 69 & 1 & 5 & $17.1 \%$ & 180 & 19 & 10 & $82.9 \%$ \\
\hline
\end{tabular}

Legal form

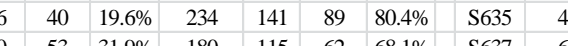

* Full NE Sample ( $\mathrm{n}=817)$

12-month follow-up (PSED item R502): Active start-up ( $\mathrm{n}=184)$, Operating business ( $\mathrm{n}=181$ )

24-month follow-up (PSED item S502): Active start-up ( $\mathrm{n}=80$ ), Operating business ( $\mathrm{n}=72$ )

36-month follow-up (PSED item T502): Active start-up (n=32), Operating business ( $\mathrm{n}=31$ ) 
Table 2: Start-up Activities Reported Complete by Nascent Entrepreneurs (Ages 22-30 only) across Waves by Venture Status (Active Start-up Vs. Operating Business)

\begin{tabular}{|c|c|c|c|c|c|c|c|c|c|c|c|c|c|c|c|c|c|c|c|c|c|c|c|c|c|c|c|c|c|c|c|c|}
\hline \multirow{3}{*}{ Start-up Activity } & \multicolumn{5}{|c|}{ Initial Screen } & \multicolumn{9}{|c|}{ 12-Month Follow Up } & \multicolumn{9}{|c|}{ 24-Month Follow Up } & \multicolumn{9}{|c|}{ 36-Month Follow Up } \\
\hline & \multirow[b]{2}{*}{$\begin{array}{c}\text { PSED } \\
\text { Item }\end{array}$} & \multirow[b]{2}{*}{ Yes } & \multirow[b]{2}{*}{$\%$} & \multirow[b]{2}{*}{ No } & \multirow[b]{2}{*}{$\%$} & \multirow[b]{2}{*}{$\begin{array}{c}\text { PSED } \\
\text { Item }\end{array}$} & \multicolumn{3}{|c|}{ Yes } & \multirow[t]{2}{*}{$\%$} & \multicolumn{3}{|c|}{ No } & \multirow[t]{2}{*}{$\%$} & \multirow[b]{2}{*}{$\begin{array}{c}\text { PSED } \\
\text { Item }\end{array}$} & \multicolumn{3}{|c|}{ Yes } & \multirow[t]{2}{*}{$\%$} & \multicolumn{3}{|c|}{ No } & \multirow[t]{2}{*}{$\%$} & & & Yes & & $\%$ & & No & & $\%$ \\
\hline & & & & & & & $\begin{array}{c}\text { Full } \\
\text { sample }\end{array}$ & $\begin{array}{l}\text { Act. } \\
\text { S-up }\end{array}$ & $\begin{array}{c}\text { Oper. } \\
\text { Bus. }\end{array}$ & & $\begin{array}{c}\text { Full } \\
\text { sample }\end{array}$ & $\begin{array}{l}\text { Act. } \\
\text { S-up }\end{array}$ & $\begin{array}{c}\text { Oper. } \\
\text { Bus. }\end{array}$ & & & $\begin{array}{c}\text { Full } \\
\text { sample }\end{array}$ & $\begin{array}{l}\text { Act. } \\
\text { S-up }\end{array}$ & $\begin{array}{c}\text { Oper. } \\
\text { Bus. }\end{array}$ & & $\begin{array}{c}\text { Full } \\
\text { sample }\end{array}$ & $\begin{array}{l}\text { Act. } \\
\text { S-up }\end{array}$ & $\begin{array}{c}\text { Oper. } \\
\text { Bus. }\end{array}$ & & $\begin{array}{c}\text { PSED } \\
\text { Item }\end{array}$ & $\begin{array}{c}\text { Full } \\
\text { sample }\end{array}$ & $\begin{array}{l}\text { Act. } \\
\text { S-up }\end{array}$ & $\begin{array}{c}\text { Oper. } \\
\text { Bus. }\end{array}$ & & $\begin{array}{c}\text { Full } \\
\text { sample }\end{array}$ & $\begin{array}{l}\text { Act. } \\
\text { S-up }\end{array}$ & $\begin{array}{c}\text { Oper. } \\
\text { Bus. }\end{array}$ & \\
\hline Organized team & Q116 & 102 & $65.0 \%$ & 55 & $35.0 \%$ & R573 & 5 & 1 & 4 & $31.3 \%$ & 11 & 9 & 2 & $68.8 \%$ & S573 & 2 & 3 & 1 & $20.0 \%$ & 12 & 13 & 3 & $80.0 \%$ & \begin{tabular}{c|c|} 
T573 \\
\end{tabular} & 9 & 1 & 0 & $33.3 \%$ & 16 & 2 & 0 & $66.7 \%$ \\
\hline Prepared business plan & Q111 & 104 & $65.8 \%$ & 54 & $34.2 \%$ & R568 & 35 & 21 & 14 & $67.3 \%$ & 17 & 8 & 9 & $32.7 \%$ & S568 & 38 & 11 & 10 & $77.8 \%$ & 12 & 5 & 1 & $22.2 \%$ & T568 & 44 & 4 & 2 & $66.7 \%$ & 19 & 1 & 2 & $33.3 \%$ \\
\hline Bought facilities / equipment & Q131 & 70 & $44.6 \%$ & 87 & $55.4 \%$ & R588 & 13 & 9 & 4 & $56.5 \%$ & 10 & 8 & 2 & $43.5 \%$ & S588 & 9 & 2 & 2 & $36.4 \%$ & 14 & 4 & 3 & $63.6 \%$ & $\mathrm{~T} 588$ & 13 & 0 & 0 & $0.0 \%$ & 18 & 1 & 0 & $100.0 \%$ \\
\hline Invested own money & Q143 & 138 & $87.3 \%$ & 20 & $12.7 \%$ & R600 & 6 & 3 & 3 & $75.0 \%$ & 2 & 1 & 1 & $25.0 \%$ & 5600 & 5 & 1 & 2 & $10.3 \%$ & 1 & 15 & 11 & $89.7 \%$ & $\mathrm{~T} 600$ & 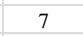 & 1 & 0 & $100.0 \%$ & 1 & 0 & 0 & $0.0 \%$ \\
\hline Asked for funding & Q145 & 35 & $22.4 \%$ & 121 & $77.6 \%$ & $\mathrm{R} 602$ & 9 & 6 & 3 & $25.0 \%$ & 27 & 17 & 10 & $75.0 \%$ & S602 & 11 & 3 & 1 & $23.5 \%$ & 23 & 8 & 5 & $76.5 \%$ & T602 & 11 & 0 & 1 & $20.0 \%$ & 33 & 2 & 2 & $80.0 \%$ \\
\hline Devoted full time & Q153 & 41 & $25.9 \%$ & 117 & $74.1 \%$ & R610 & 10 & 6 & 4 & $29.4 \%$ & 24 & 18 & 6 & $70.6 \%$ & S610 & 7 & 1 & 4 & $29.4 \%$ & 22 & 11 & 1 & $70.6 \%$ & T610 & 9 & 1 & 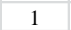 & $40.0 \%$ & 30 & 2 & 1 & $60.0 \%$ \\
\hline Patent/copyright & Q124 & 21 & $13.3 \%$ & 137 & $86.7 \%$ & R581 & 6 & 3 & 3 & $15.4 \%$ & 33 & 16 & 17 & $84.6 \%$ & S581 & 1 & 11 & 6 & $73.9 \%$ & 34 & 5 & 1 & $26.1 \%$ & T581 & 52 & 0 & 0 & $0.0 \%$ & 1 & 2 & 4 & $100.0 \%$ \\
\hline Hired employees & Q155 & 16 & $10.1 \%$ & 142 & $89.9 \%$ & R612 & 11 & 6 & 5 & $25.6 \%$ & 32 & 22 & 10 & $74.4 \%$ & S612 & 10 & 1 & 5 & $26.1 \%$ & 31 & 12 & 5 & $73.9 \%$ & $\mathrm{~T} 612$ & 5 & 1 & 0 & $14.3 \%$ & 48 & 3 & 3 & $85.7 \%$ \\
\hline Saved money & Q139 & 125 & $79.6 \%$ & 32 & $20.4 \%$ & R596 & 4 & 1 & 3 & $28.6 \%$ & 10 & 6 & 4 & $71.4 \%$ & S596 & 2 & 2 & 0 & $12.5 \%$ & 5 & 14 & 0 & $87.5 \%$ & T596 & 4 & 1 & 0 & $50.0 \%$ & 11 & 0 & 1 & $50.0 \%$ \\
\hline Banking account & Q160 & 40 & $26.3 \%$ & 112 & $73.7 \%$ & R617 & 15 & 4 & 11 & $42.9 \%$ & 20 & 19 & 1 & $57.1 \%$ & S617 & 15 & 7 & 3 & $41.7 \%$ & 20 & 9 & 5 & $58.3 \%$ & T617 & 15 & 2 & 1 & $37.5 \%$ & 28 & 3 & 2 & $62.5 \%$ \\
\hline Contact information & Q171 & 25 & $16.0 \%$ & 131 & $84.0 \%$ & R629 & 5 & 2 & 3 & $13.9 \%$ & 31 & 24 & 7 & $86.1 \%$ & S629 & 6 & 1 & 9 & $37.0 \%$ & 33 & 13 & 4 & 63.0 & $\mathrm{~T} 629$ & 0 & 0 & 0 & $0.0 \%$ & 46 & 5 & 3 & $100.0 \%$ \\
\hline Marketing & Q122 & 80 & $50.6 \%$ & 78 & $49.4 \%$ & R579 & 13 & 7 & 6 & $31.7 \%$ & 8 & 8 & 20 & $68.3 \%$ & S579 & 6 & 3 & 2 & $23.8 \%$ & 12 & 13 & 3 & $76.2 \%$ & T579 & 7 & 0 & 0 & $0.0 \%$ & 17 & 3 & 0 & $100.0 \%$ \\
\hline Raw material & $\mathrm{Q} 128$ & 107 & $67.7 \%$ & 51 & $32.3 \%$ & R585 & 6 & 4 & 2 & $17.1 \%$ & 5 & 5 & 24 & $82.9 \%$ & 5585 & 11 & 4 & 3 & $35.0 \%$ & 7 & 3 & 10 & $65.0 \%$ & T585 & 12 & 0 & 0 & $0.0 \%$ & 9 & 1 & 0 & $100.0 \%$ \\
\hline Gathering information & Q134 & 135 & $85.4 \%$ & 23 & $14.6 \%$ & R591 & 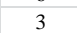 & 3 & 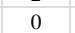 & $60.0 \%$ & 2 & 2 & 0 & $40.0 \%$ & S591 & 5 & 2 & 2 & $25.0 \%$ & 1 & 1 & 11 & $75.0 \%$ & T591 & 11 & 2 & 1 & $100.0 \%$ & 3 & 0 & 0 & $0.0 \%$ \\
\hline Contact assistance program & Q303 & 18 & $11.6 \%$ & 137 & $88.4 \%$ & $\mathrm{R}$ & 3 & 2 & 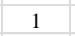 & $6.8 \%$ & 41 & 24 & 17 & $93.2 \%$ & 5755 & 8 & 3 & 2 & $20.8 \%$ & 31 & 10 & 9 & 79. & $\mathrm{~T}$ & 4 & 0 & 1 & $14.3 \%$ & 22 & 5 & 1 & $85.7 \%$ \\
\hline Legal form & Q175 & 9 & $5.9 \%$ & 143 & $94.1 \%$ & R633 & 4 & 27 & 4 & $62.0 \%$ & 42 & 4 & 15 & $38.0 \%$ & S633 & 4 & 15 & 3 & $69.2 \%$ & 39 & 1 & 7 & $30.8 \%$ & $\mathrm{~T} 633$ & 8 & 0 & 1 & $11.1 \%$ & 50 & 5 & 3 & $88.9 \%$ \\
\hline Legal form & Q177 & 14 & $9.2 \%$ & 139 & $90.8 \%$ & R635 & 6 & 1 & 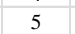 & $13.3 \%$ & 39 & 25 & 14 & $86.7 \%$ & S635 & 8 & 1 & 5 & $27.3 \%$ & 30 & 12 & 4 & $72.7 \%$ & T635 & 11 & 0 & 0 & $0.0 \%$ & 41 & 3 & 2 & $100.0 \%$ \\
\hline Legal form & Q179 & 22 & $14.2 \%$ & 133 & $85.8 \%$ & R637 & 8 & 3 & 5 & $20.5 \%$ & 31 & 21 & 10 & $79.5 \%$ & S637 & 11 & 2 & 3 & $25.0 \%$ & 24 & 11 & 4 & $75.0 \%$ & $\mathrm{~T} 637$ & 15 & 0 & 0 & $0.0 \%$ & 29 & 3 & 2 & $100.0 \%$ \\
\hline * NE Full sample for ages 22-3 & $30(\mathrm{n}=15$ & & & & & & & & & & & & & & & & & & & & & & & & & & & & & & & \\
\hline 12-month follow-up (PSED i & item R50 & 2): Act & tive start & t-up & $n=31), O$ & ating bus & siness $(\mathrm{n}$ & $n=26)$ & & & & & & & & & & & & & & & & & & & & & & & & \\
\hline 24-month follow-up (PSED i & item S50 & 2): Act & ive start & 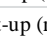 & $n=16), O$ & ting $\mathrm{bt}$ & $\operatorname{siness}(\mathrm{n}$ & $n=13)$ & & & & & & & & & & & & & & & & & & & & & & & & \\
\hline 36-month follow-up (PSED i & T50 & 2): Act & tive start & t-up & $n=5), c$ & ing $b$ & ness $(n=$ & & & & & & & & & & & & & & & & & & & & & & & & & \\
\hline
\end{tabular}

